the current standards required for the certification of marketed pharmaceuticals. One of the cases, which is referred to numerous times throughout the book, involves an individual with a chronic bone infection who was treated by irrigation with solutions containing phage and by having phage-impregnated material placed in the open wounds. It would be interesting to compare such 'phage therapy' with the use of saline irrigations and sterile drains. Although Häusler acknowledges the need for the careful development of therapeutic agents, along with the need for adequate control experiments, there is a danger that this book might encourage some individuals with infectious diseases to use phage in such a way.

The development of therapeutic phage will need a commitment to meet all the scientific requirements for current pharmaceutical agents. An anecdotal approach, adopted by some of the investigators described in the book and widely used in clinical medicine in the early twentieth century, may retard rather then stimulate the acceptance of therapeutic applications. The encouraging results of animal experiments have demonstrated phage's capacity to rescue animals with life-threatening infections. Perhaps phage therapy, if carefully developed, could provide some much-needed antibacterial agents.

Sankar Adhya is at the Laboratory of Molecular Biology, National Cancer Institute, Bethesda, Maryland 20892, USA. Carl Merril is emeritus at the Laboratory of Biochemical Genetics, National Institute of Mental Health, Bethesda, Maryland 20892, USA.

\title{
Eeyore goes to Washington
}

\author{
The Beginner's Guide to Winning the \\ Nobel Prize: A Life in Science \\ by Peter Doherty \\ Columbia University Press: 2006.320 pp. \\ $\$ 24.95$
}

\section{Peter Parham}

Soon after my appointment as an assistant professor, I was interviewed in Palm Springs for a beginner's grant given by a popular American charity. The interviewer, a bejewelled and scarily tanned doctor, looked me straight in the eyes and barked, "So, for what will you win the Nobel prize?" On hesitating to answer, my interview was doomed. I shortly crawled away, to hear nothing more of the matter. Back then, what I could have used was The Beginner's Guide to Winning the Nobel Prize. The book's author, Peter Doherty, knows about these things, because in 1996 he and Rolf Zinkernagel were awarded the Nobel Prize in Physiology or Medicine for their joint work on the recognition of virus-infected tissue by $T$ lymphocytes of the immune system.

For the aspiring young scientist, or a student considering a scientific career, Doherty opens the vault to the world of science, explaining how it works and how to get on. His title is only lightly in jest, for the last chapter gives a common-sense set of 18 guiding principles to scientific success that almost any old hand would agree with. As well as continuing
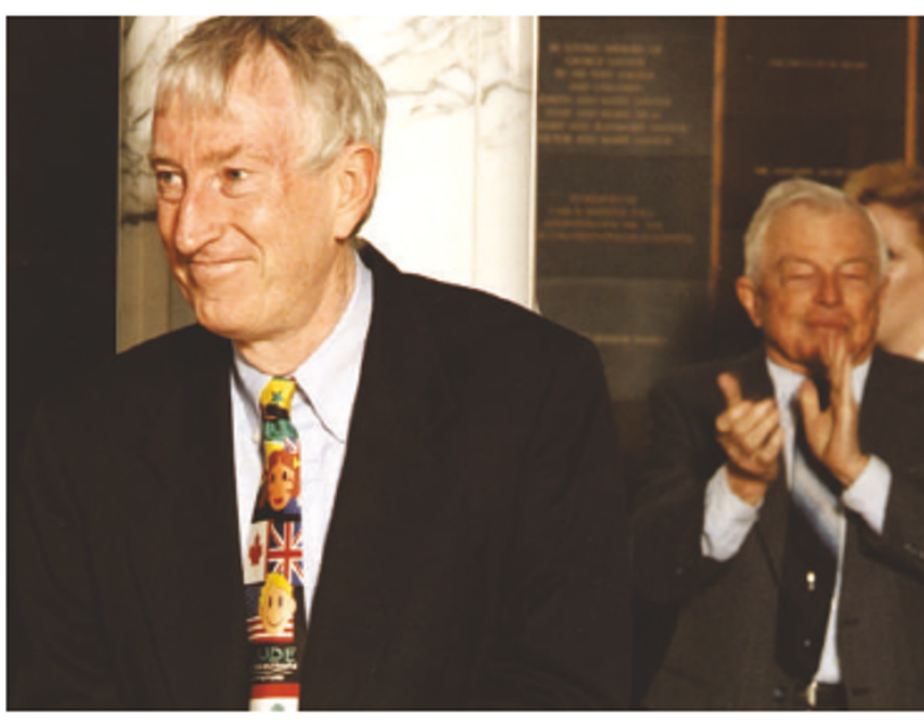

Winning a Nobel prize has given Peter Doherty a platform to air his views on climate change and the environment.

his kind, however, Doherty aims to reach a broader readership: those who learn from the movies that "scientists are always mad, bad or quaint nerds who rattle on about controlling the world".

$\mathrm{He}$ is not motivated by simple enthusiasm alone, however: like others in the know, Doherty has become deeply concerned with the way governments manipulate science to suit their political goals, and with the way publics at large, paradoxically, combine a pervasive suspicion of science with an equally pervasive confidence that technology - the application of science - can alone solve all the world's problems.

Doherty is an Australian, a veterinary surgeon and a faculty member at both St Jude Children's Research Hospital in Memphis, Tennessee, and the University of Melbourne. Once described by the eminent immunologist Philippa Marrack in The New York Times as "a bit Eeyore-like" (Eeyore being the indomitable, iflugubrious, donkey from A. A. Milne's The House at Pooh Corner), Doherty says that

\section{NEW IN PAPERBACK}

Nature: An Economic History

by Geerat J. Vermeij (Princeton

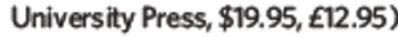

\section{On the Origin of Phyla}

by James W. Valentine

(University of Chicago Press,

$£ 22.50, \$ 35)$

"A magnificent book [about] ane of the most significant revolutions in the history of life, the Cambrian explosion." Stefan Bengtson,

Nature 430, 506 (2004).
Our Inner Ape: The Best and Worst of Human Nature

by Frans de Waal (Granta E9.99)

"In this excellent book for the public, Frans de Waal tackles some exasperating misconceptions about the evolution of the social behaviour of apes, particularly humans." Robert Sapolsky, Nature 437, 33-34(2005).
The Tree: A Natural History of What Trees Are, How They Live, and Why They Matter by Colin Tudge (Crown Publishers, \$27.95)

Pandora's Baby: How the First Test Tube Babies Sparked the Reproductive Revolution by Robin Marantz Henig (Cold Spring Harbor Laboratory Press, \$15.95)
The Equation That Couldn't Be Solved: How Mathematical Genius Discovered the Language of Symmetry by Mario Livio (Simon \& Schuster, \$15)

"Mario Livio follows [Galois'] brief existence like a sleuth... and gives a panoramic view of the direct, as well as quite remote, applications of group theory." István Hargittai, Nature 437, 34 (2005). 